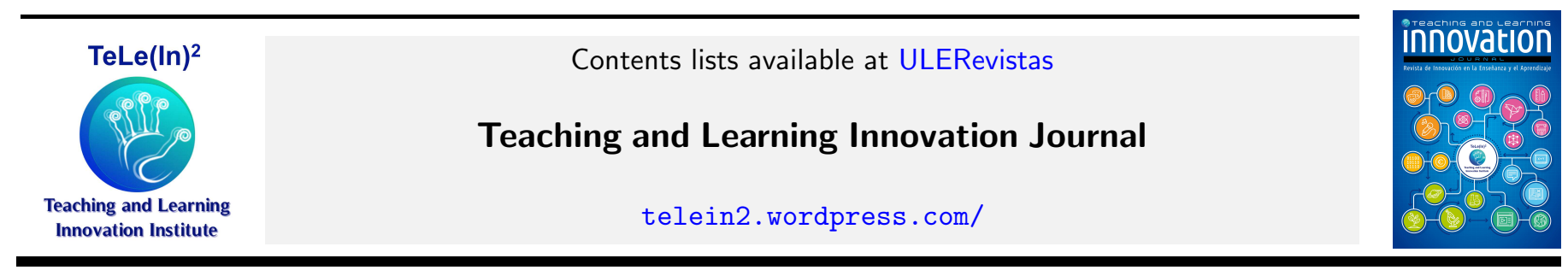

\title{
Optimizando la complejidad para mejorar el aprendizaje Optimising Complexity to Improve Learning
}

\author{
Dr. Bruce Hilliard ${ }^{\mathrm{a}}$, Dr. Jocelyn Armarego ${ }^{\mathrm{a}}$ \\ ${ }^{a}$ School of Engineering $\&$ Information Technology, Murdoch University, Perth, Australia
}

\begin{abstract}
Este estudio trata sobre un elemento clave de diseño, relacionado con el nivel de complejidad del material visual, y su efecto sobre la comprensión e impresiones sobre la audiencia. Para cuantificar este efecto, se ha desarrollado un modelo indicativo de la curva de complejidad, basándose en investigaciones previas sobre este tema. Esta curva de complejidad ha mostrado que una complejidad moderada, tiende a producir resultados óptimos de aprendizaje. Para probar este modelo, se crearon una serie de presentaciones control, con la aplicación de complejidad moderada. Después, se desarrollaron variaciones de estas presentaciones. La única diferencia entre las presentaciones control y las variaciones fue la aplicación de cambios específicos en la complejidad de los elementos visuales. Los cambios incluyeron el uso de imágenes incongruentes, que tenían contenido de muy baja complejidad y se fue aumentando la complejidad con la adición de animaciones superfluas. Los datos sobre la comprensión y las impresiones fue recopilada a través de un proceso experimental formal. Los datos recogidos indican que la curva de complejidad desarrollada a partir de estos datos, es válida. Estos resultados tienen implicaciones importantes para el diseño del aprendizaje y todas las formas de diseño visual basado en ordenador.

This paper addresses a key element of design, which relates to the level of complexity in the visual material, and its effect on viewer comprehension and impressions. To help quantify this effect, an indicative Complexity Curve model was developed from previous research on the topic. This Complexity Curve showed that moderate complexity was most likely to produce optimal learning outcomes. To test this model, a series of Control Presentations were created, which applied moderate complexity. Variants of these presentations were then developed, so the only difference between the control and variant presentations was the application of specific changes in the complexity of the visualisation. These included the use of incongruent pictures, providing very low complexity content, and increasing the complexity by adding extraneous animations. Comprehension and impressions data was then collected through a formal experimental process. This collected data indicated that the developed Complexity Curve appeared to have validity. These results hold important implications for learning design and all forms of computer-based visual design.
\end{abstract}

Keywords: Educación, Diseño de aprendizaje, psicología, psicofísica, Teoría cognitiva de carga, Ciencia Cognitiva Education, Learning Design, Psychology, Psychophysics, Cognitive Load Theory, Cognitive Science

\section{Introduction}

To create a science-based holistic model for optimising the use of visuals in learning, Hilliard (2016) developed a Unified Design Model (UDM) and an associated set of practical design guidelines. The UDM and guidelines addressed the attributes illustrated in Figure 1.

As indicated in the design of Figure 1, an overarching issue that affects, and is affected by, all of the other at-

Email addresses: b.hilliard@murdoch.edu.au (Dr. Bruce Hilliard), j.armarego@murdoch.edu.au (Dr. Jocelyn Armarego) tributes is complexity. In this context, complexity refers to 'the number of independent features of the stimuli', 'the number and variability of the elements, and a factor related with the overall structure of the elements' (Roberts, 2007, pp. 22-23). According to Tufte (1990) inappropriate use of complexity within the visual material can adversely affect the communication of information.

For example, visual complexity can directly impact on the effectiveness of memory retention (Tuch, Bargas-Avila, Opwis, \& Wilhelm, 2009), attention, impressions (Geissler, Zinkhan, \& Watson, 2006), task performance, and the 


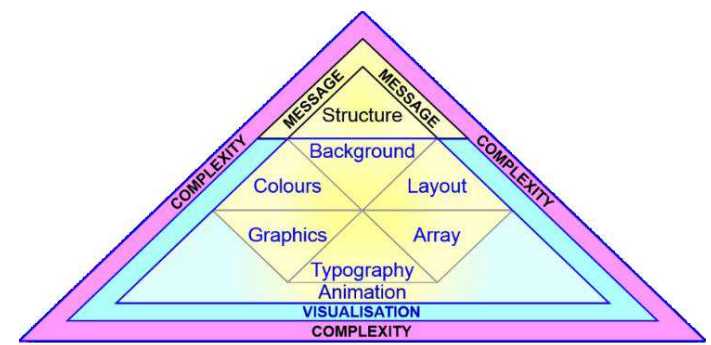

Figure 1: The attributes in the Unified Design Model (UDM)

viewer's experience of pleasure and arousal ( $\mathrm{Wu}, \mathrm{Hu}, \&$ Shi, 2013).

However, a detailed analysis of guidance in design and psychological publications, which was carried out in Hilliard (2016), identified that there was a paucity of detailed guidelines on managing complexity. This paper focusses on just one key element of this management, which relates to the level of complexity that should be applied when designing visual materials, such as PowerPoint presentations, web pages and eLearning systems.

\section{Context}

The level of complexity can be affected by a range of visual and content design factors (Bennett, Toms, \& Woods, 1993; Donderi, 2006; Tufte, 1997, 2001; Vitz, 1966). For instance, Roberts (2007) identified aspects such as the variety of elements on the screen, the potential for object recognition, scene organisation (gist), and aspects such as symmetry or asymmetry, as key design factors that affect the discernment of complexity.

Additionally, the colour combinations used (Cummings \& Tsonis, 2006; Pathiavadi, 2009), pictorial/graphical design techniques applied (De Westelinck, Valcke, De Craene, \& Kirschner, 2005; Makaramanee, 1985; Moreno \& Mayer, 1999), the typography utilised (Green, 1981; Rayner, Reichle, Stroud, Williams, \& Pollatsek, 2006), and the animations that are implemented (Huff \& Schwan, 2011; Mineo, Peischl, \& Pennington, 2008; Schnotz \& Rasch, 2005) also directly influence viewer assessments of complexity.

In other words, levels of complexity are influenced singly and jointly by each of the other design attributes shown in Figure 1. The key question, however, is how much complexity is appropriate to optimise communication and learning?

\section{A. How much complexity is appropriate?}

Presentation design experts such as Duarte (2008), Reynolds (2010, 2012), Gabrielle (2010) and Kosslyn (2007) each talk about simplification of the visual content, but an analysis of their books indicated that extreme simplicity was not their aim. Alternately, Schnotz and Kurschner (2007) identified that both low complexity and high complexity material also produced suboptimal communications outcomes. Consequently, the application of moderate complexity appeared to be an optimal design choice. This concept is illustrated in Figure 3, which correlates complexity with a viewer's attention, preferences (impressions), and interest.

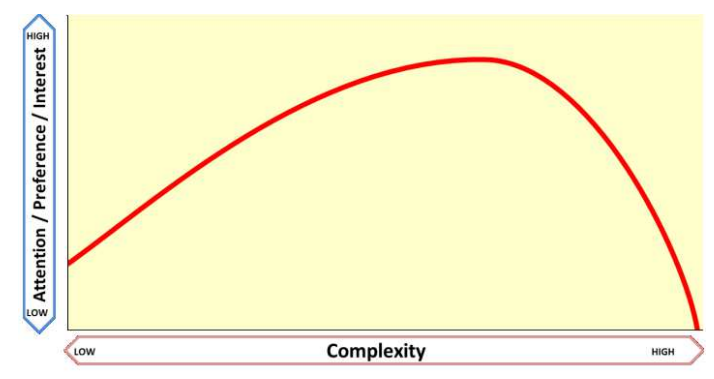

Figure 2: The effects of complexity on attention, preferences and interest (Complexity Curve)

Figure 3 was developed by rationalising and coalescing information provided in Vitz (1966), Wang, Yang, Liu, Cao, and Ma (2014), Berlyne (1970), Day (1967), Hillyard (1979), Roberts (2007), Thorson, Reeves, and Schleuder (1985), McNamara, Kintsch, Songer, and Kintsch (1996), Surenda, Nikunj, and Spears (2005), Geissler, Zinkhand, and Watson (2006), Granger (2012), Schnotz and Kurschner (2007), and Schnotz and Rasch (2005).

As illustrated in this Complexity Curve, the following aspects appear to characterise the effects of varying complexity:

- Low complexity. Low levels of complexity may only generate:

$>$ minimal attention and interest (Geissler et al., 2006);

$>$ decreased levels of arousal and lower impressions ratings (Berlyne, 1963; Roberts, 2007; Terwilliger,1963); and

> reduced learning outcomes (McNamara et al., 1996), which are possibly associated with viewers' lower levels of attention and impressions (Balfanz, Herzog, \& Mac Iver, 2007; Marks, 2000).

- Moderate complexity. Moderate complexity can significantly increase acceptance of the information, the level of attention, and viewer preferences (Geissler et al.,2006; Roberts, 2007; Surenda et al., 2005; Vitz, 1966). However, the complexity must be aligned to the delivery and processing of the key material, and designers should avoid increasing complexity through extraneous content or visualisations (Brunken, Plass, \& Leutner, 2004; Paas, vanGog, \& Sweller, 2010; Schnotz \& Kurschner, 2007). 
- Higher complexity. Once the complexity of the material exceeds working memory capacity it becomes counter-productive, and attention, preferences and interest can fall significantly (Brunken et al., 2004; Butcher, 2003;McNamara et al., 1996; Schnotz \& Rasch, 2005; Vitz,1966).

\section{B. Understanding the validity of the model}

However, the Complexity Curve shown at Figure 3 could only be considered an indicative model, because the guidance in each of the contributing publications differed substantially. For example, many publications used dissimilar slope diagrams, or provided no direct indication of the curve at all. Consequently, this figure just applied one generalised slope for the Complexity Curve, which leveraged the content defined in Vitz (1966).

\section{Description}

\section{A. Overview of the research process}

To assist in determining the validity of this Complexity Curve model, a set of experiments were conducted within the framework of the UDM research explained in Hilliard (2016). This approach entailed the following phases:

- Phase 1. An extensive study into each of the various attributes was conducted using material collected from design publications, and research in the fields of neuroscience, psychophysics, biopsychology and cognitive science. From more than 1600 publications analysed in this phase, a set of tentative design principles was developed.These tentative principles rationalised and amalgamated a wide range of narrowly focussed experiments, so they could be used to create a holistic design methodology.

- Phase 2. The tentative principles were then applied to create a set of Control Presentations (CP), which reflected the design advice gleaned from a wide range of earlier research. In particular, these CP were designed to fundamentally apply moderate complexity, by using the techniques explained in Hilliard (2016). Each of these CP explained various maths related subjects, which were separated into discreet Numeracy Modules (NM).Additionally, a range of ambiguities were identified in the Phase 1 research (e.g. previous experiments presenting contradictory findings, or key aspects not being clarified by earlier research). To investigate these ambiguities, variations of each $\mathrm{CP}$ were created. These modified versions of the CP covered the same numeracy content, but the visualisation techniques applied in these Variant Presentations (VP) were modified in carefully defined ways that allowed specific hypotheses to be investigated.

- Phase 3. Participants from Murdoch University were separated into groups using Stratified Random
Allocation techniques, to balance key demographic attributes and numeracy skill levels across the groups. Each participant in the experiments then accessed the experimental materials online, through the Learning Management System (LMS). They then carried out the following steps at their own pace, and at a time that was convenient for them:

> Step 1. Each participant completed a standard Diagnostic Test (DT) to determine their level of knowledge related to the NM, prior to them viewing the stand-alone visual presentation.

> Step 2. After completing the DT, each person viewed either the CP or VP PowerPoint presentation for that NM. The CP or VP versions that they were allowed to view were carefully controlled by the LMS, so everyone in specific groups viewed the same CP or VP.

$>$ Step 3. As soon as possible after finishing Step 2, each participant was asked to complete a Post Test (PT).The PT included similar questions to the DT, so differences in test outcomes could be identified.

Step 4. The participants were then requested to answer a set of standard impressions questions. These impressions surveys included ten questions that were answered by making selections within a Likert Scale response list (e.g. Strongly Disagree to Strongly Agree). Each of these questions was specifically mapped to the attributes within the UDM, so different effects could be isolated. Additionally, two qualitative questions were included, to find out what they liked most or least about the presentation they had viewed.

- Phase 4. The collected response data was then analysed to determine the following:

$>$ Comprehension. Differences in test scores between the DT and PT were used to identify how much of the visual information had been comprehended. As the maths content in both the $\mathrm{CP}$ and VP were the same,the key differences generated in the data should have been related to the changes in visualisation.

$>$ Impressions. The impressions surveys used the same questions for the groups viewing either a CP or VP.Their Likert Scale responses were quantified for scoring purposes on a continuum from 1 (Strongly Disagree) to 5 (Strongly Agree). These collected data were used to identify differences in impressions for members of the groups, and therefore demonstrate how variations in the visualisation influenced viewer feelings. 
Table 1: Participants in each set of experiments - and as delineated by key demographic/physiological variables

\begin{tabular}{|c|c|c|c|c|c|c|c|c|}
\hline & \begin{tabular}{|l|} 
Experiment Set \\
\end{tabular} & \begin{tabular}{|l|} 
Numeracy \\
Module \# \\
\end{tabular} & $\mathrm{n}$ & $\begin{array}{c}\mathrm{n} \text { by Gender } \\
\text { (Male / Female) }\end{array}$ & $\begin{array}{c}\mathrm{n} \text { by Age Group } \\
(18-30 / 31-50 />50)\end{array}$ & \begin{tabular}{l|}
$\mathrm{n}$ by English as First \\
Language (Yes / No)
\end{tabular} & $\begin{array}{c}\mathrm{n} \text { by Vision Problems } \\
(\text { Yes / No) }\end{array}$ & $\begin{array}{c}\mathrm{n} \text { by Colour Blindness } \\
(\text { Yes / No) }\end{array}$ \\
\hline \multirow{6}{*}{ 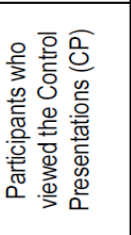 } & \multirow[t]{2}{*}{ Incongruence } & 5 & 117 & $27 / 90$ & $92 / 24 / 1$ & $103 / 14$ & $5 / 112$ & $1 / 116$ \\
\hline & & 14 & 95 & $35 / 60$ & $74 / 19 / 2$ & $81 / 14$ & $7 / 88$ & $3 / 92$ \\
\hline & \multirow[t]{2}{*}{ Low complexity } & 2 & 126 & $33 / 93$ & $96 / 26 / 4$ & $109 / 17$ & $7 / 119$ & $2 / 124$ \\
\hline & & 9 & 195 & $53 / 142$ & $163 / 28 / 4$ & $169 / 26$ & $5 / 190$ & $2 / 193$ \\
\hline & \multirow[t]{2}{*}{ High complexity } & 6 & 114 & $35 / 79$ & $88 / 20 / 6$ & $100 / 14$ & $8 / 106$ & $1 / 113$ \\
\hline & & 10 & 171 & $64 / 107$ & $125 / 42 / 4$ & $160 / 11$ & $3 / 168$ & $2 / 169$ \\
\hline \multirow{6}{*}{ 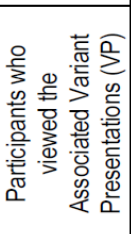 } & \multirow[t]{2}{*}{ Incongruence } & 5 & 66 & $22 / 44$ & $54 / 11 / 1$ & $58 / 8$ & $1 / 65$ & $1 / 65$ \\
\hline & & 14 & 148 & $39 / 109$ & $123 / 23 / 2$ & $128 / 20$ & $7 / 141$ & $1 / 147$ \\
\hline & \multirow[t]{2}{*}{ Low complexity } & 2 & 218 & $61 / 157$ & $189 / 25 / 4$ & $293 / 25$ & $10 / 208$ & $3 / 215$ \\
\hline & & 9 & 141 & $46 / 95$ & $106 / 31 / 4$ & $125 / 16$ & $5 / 136$ & $2 / 139$ \\
\hline & \multirow[t]{2}{*}{\begin{tabular}{|l|} 
High complexity \\
\end{tabular}} & 6 & 35 & $14 / 21$ & $25 / 9 / 1$ & $32 / 3$ & $0 / 35$ & $1 / 34$ \\
\hline & & 10 & 178 & $44 / 134$ & $142 / 32 / 4$ & $152 / 26$ & $7 / 171$ & $1 / 177$ \\
\hline
\end{tabular}

Figure 3: The effects of complexity on attention, preferences and interest (Complexity Curve)

\section{B. Specific experiments covered in this paper}

Three sets of interrelated experiments were implemented, to test the hypothesis (H1) that moderate complexity (as achieved through the application of the identified tentative principles in the CPs), enhanced viewer comprehension and impressions. The three sets of experiments can be categorised as follows:

- Incongruence. The CP for each NM was designed to utilise reinforcement of the text-based message through a range of different techniques. One of these techniques included the application of congruent reinforcing graphics, which were designed to assist the viewer to understand and retain information related to the text. VPs were developed for two NM (Modules 5 and 14). These were designed to modify the $\mathrm{CP}$ approach, and moderately increase complexity. The technique entailed removing the congruent reinforcing graphics and replacing them with pictures of clowns (Module 5) or cats (Module 14), which had nothing to do with the topic being discussed.According to Rauterberg (1994) this type of approach should have increased the level of complexity in a relatively subtle fashion. Consequently, it was hoped that these sets of experiments would assist in defining the peak of the complexity curve in relation to the moderately complex CPs.

- Low complexity. Two VPs were created to substantially reduce visual complexity. These were created for NMs 2and 9. In practice, these changes reduced the level of visual complexity to a state similar to the utilisation of a simple overhead projector slide, or a book printed in black and white. To achieve this objective all chromatic colours, non-essential graphics, and animations, were removed from the slides. This set of experiments aimed to help determine whether the lower part of the Complexity Curve could be validated.
- High Complexity. These VPs changed the animation sequences used in the associated CPs. The changes were applied to variants in Modules 6 and 10 content. This meant that none of the other graphics or text elements used in the associated $\mathrm{CP}$ were affected. However, the animations were designed to significantly increase complexity and cognitive load. For example, multiple simultaneous, complex, inconsistent, and unnecessary animations were applied. This set of experiments was therefore designed to investigate the effect at the upper end of the Complexity Curve.

\section{Participants}

Table 1 shows the number of participants who completed the experiments appropriately, so their data could be included in the analysis. This table also delineates the participants in terms of key characteristics, which were used to determine if other independent variables may have been influencing the outcomes of the experimentation. These characteristics included gender, age group, whether English was their first language (EFL) (as they had to read the content), whether they had vision problems that could affect their ability to view the content properly, and whether they were colour blind.

As the participants were allocated specifically to each set of experiments, the groups were separate and independent. Consequently, the differences in the individual and aggregated results achieved by those people who viewed the $\mathrm{CP}$ or associated VP could be assessed to determine variance.

In particular, this meant that the influences of the dissimilarities in visualisation applied in the variants could also be separated effectively from other demographic (i.e. gender, age, EFL) or physiological factors (i.e. vision problems, colour blindness). 


\section{Results}

\section{A. Utilising the Collected Data}

The results from the various sets of experiments were assessed in terms of the differences between the comprehension scores achieved, and the impressions responses allocated by individuals, who viewed either the CP or the associated VP. The collected data was then analysed through statistical measures that included the following:

- Cohen's d Effect. As shown in Table 2, the mean improvements in test score for each group viewing either the CP or associated VP were collated. Similarly, the mean Likert scores from the impressions surveys for each group were also averaged. The effect size was then calculated using Cohen's d formula. The associated effect size descriptions provided in Table 2 conform to the advice provided in Cohen (1988) and Rosenthal (1996).

- Univariate General Linear Model (UGLM). UGLM calculations were carried out to assess variance influenced by differences in the visualisation, as well as gender, age, EFL, vision problems and colour blindness. The results are illustrated in the right hand columns of Table 2 .However, for the purposes of brevity, this table only gives the data for the effects attributable to the changes in visualisation, once all other insignificant demographic and physiological factors had been removed from the calculation. The assessment of significance was made in relation to the significance level of $5 \%(\alpha=0.05)$. A more detailed description of the effects related to the demographic and physiological factors is provided in Hilliard (2016).

\section{B. Explaining the results}

As illustrated by the information provided in Table 2, the results from the different sets of experiments can be categorised as follows:

- Incongruence. Although the average comprehension related improvement in both Module 5 and 14 was lower for the variant group, the differences between the CPs and associated VPs were not significant. This outcome was also supported by Cohen's $\mathrm{d}$, which identified that the effect of adding the incongruent graphics had a small influence on the comprehension outcomes. Alternately,there were mixed impressions results achieved in the sets of experiments conducted for Modules 5 and 14. For instance, the impressions differences between the groups were not significant in Module 5, but they were in Module14. These differences were also reflected in the effect sizes for the two sets of experiments, with Module 14 achieving a Cohen's d outcome that was approaching the moderate classification. In summary, therefore, the application of incongruent graphics did not appear to have affected the level of complexity enough to influence the comprehension results significantly. Alternatively, the impressions were adversely affected significantly in Module 14 . The causation for this difference was investigated in Hilliard (2016), but the outcomes relate to issues that are beyond the scope of this paper.

- Low Complexity. In these sets of experiments, the provision of very low complexity content in the VP did not create a significant effect in relation to the outcomes achieved by those viewing the moderately complex CP versions. However, the impressions results for both sets of experiments were significantly lower for the VP groups. Additionally, Cohen's d demonstrated that the effect size was large.

- High Complexity. The high complexity VPs produced the most dramatic effects. For example, the comprehension results for the VPs in both sets of experiments were significantly lower than those for the associated CP. Furthermore, the Cohen's d identified that the effect size was medium for comprehension differences. By far the most substantial effect, however, was on viewer impressions. As shown in Table 2 , the effect size was assessed as large (Module 6) and very large (Module 10), with the VPs producing significantly lower impressions outcomes. Just as importantly, there was a very high drop-out rate from the $\mathrm{VP}$ viewing groups in these experiments.For instance, only 35 participants actually bothered to complete the VP experiment for Module 6. This low number reflects the fact that 169 participants simply did not bother to finish the required tasks properly (e.g. did not finish viewing the presentation). The high drop-out rate is likely to be the result of the negative impressions generated by the variant treatment. These negative feelings were illustrated by viewer comments, which indicated that this treatment was 'confusing' (e.g. from Participants 5058,5286, 8010), 'annoying' (e.g. from Participants 5286,5786, 8004), 'frustrating' (e.g. from Participants $6039,6327,8016$ ), and 'hard to watch' (from Participant 5921).

\section{Discussion}

To assist in understanding how these differences reflect the effects of complexity, Figure 3 plots the variance between the mean comprehension and mean impressions scores for the CP and VP in each set of experiments. The $\mathrm{x}$-axis in this graph delineates the differences in comprehension (e.g. control minus variant). The y-axis shows the differences between the mean impressions for the $\mathrm{CP}$ and VP (e.g. variant minus control). The differences for each of the sets of experiments are shown within the scatterplot utilising specific icons, to make it easier to identify 
the different groups of complexity levels. These icons are explained in the chart legend. The polynomial trend line is based on the formula shown at the bottom right hand corner of the graph.

The first striking aspect of this graph is the holistic similarity between the trend line in this plot and the complexity graph shown in Figure 2. In particular, the level of complexity appears to have affected the outcomes as follows:

- Low complexity. In these sets of experiments there was very little difference in the comprehension for the control and variant groups. However, these variants provided substantially lower impressions outcomes than their associated controls. Consequently, the low complexity in this case provided worse impressions outcomes than the moderate complexity applied in the controls.

- Moderate complexity. As discussed earlier, the incongruence experiments were designed to provide somewhat more complexity than the control. Figure 3shows that this treatment generated impressions outcomes that were closer to the results from the controls, than those achieved by either of the other two sets of experiments. In other words, this treatment appears to have been closer to the top of the Complexity Curve than the other complexity related variants. However, it is noteworthy that these experiments produced lower comprehension and impressions results than the associated CPs, so the level of complexity in these VPs appears to have gone beyond the peak of the identified Complexity Curve.

- High complexity. This treatment generated the lowest comprehension and impressions results. High complexity therefore appears to have provided visual stimuli that was well past the peak of the curve. It is particularly noteworthy that this outcome was achieved by simply adding extraneous animations to the presentations.

Consequently, the following can be surmised from these three sets of experiments:

- The research used to develop the model in Figure 2 appears to have been validated by these experiments, as the optimal approach leveraged moderate complexity.

- The hypothesis (H1) was supported, because the moderate complexity applied in the controls produced the highest comprehension and impressions outcomes.

\section{Limitations and other factors}

Although the data produced clear results that have helped to quantify the Complexity Curve, the results also appear to have been influenced by demographic and physiological factors. For instance, the negative impressions identified in the low complexity sets of experiments may have been influenced by the ages of the participants. As shown in Table 1, more than $81 \%$ of the participants who viewed the low complexity content were in the 18-30 age group. This age factor was identified as having a significant influence on the impressions results in both Module $2(\mathrm{MS}=2.969, \mathrm{~F}=10.430, \mathrm{p} ; 0.001)$ and Module 9 (MS $=1.927, \mathrm{~F}=7.723, \mathrm{p}=0.001)$. Consequently, although these issues were taken into account within the statistical analysis, it is possible that the negative impressions related to the low complexity treatment may have been due to the different expectations of the younger participants. As an example, it is possible that the younger participants would have higher expectations about the use of colour and animation, than older participants. For this reason, further clarification of the issues is apropos.

A range of additional issues are also discussed in Hilliard (2016), but for the sake of brevity they are not addressed in this paper.

\section{E. Further investigation}

Although these sets of experiments support the general tenets of the Complexity Curve approach, they do not provide enough specific data to rationalise and validate the slope of the curvature, so this concept can be utilised more rigorously in design. Follow-up investigation will therefore require a series of specific experiments that just focus on refining the complexity related guidelines explained in Hilliard (2016).

\section{Conclusions}

This paper was designed to explain just one important aspect of design, which relates to complexity. As identified in the Complexity Curve, the objective should typically be to develop content that reflects moderate complexity, and this can be achieved by carefully controlling the attributes such as the message structure, colour, backgrounds, layout, arraying of the visual material, typography, graphics and animation.

Such management of the material is important, because the failure to provide moderate complexity can adversely affect comprehension of the content, and create negative impressions. Consequently, these issues need to be taken into account by anyone designing presentations, web pages or eLearning systems. 


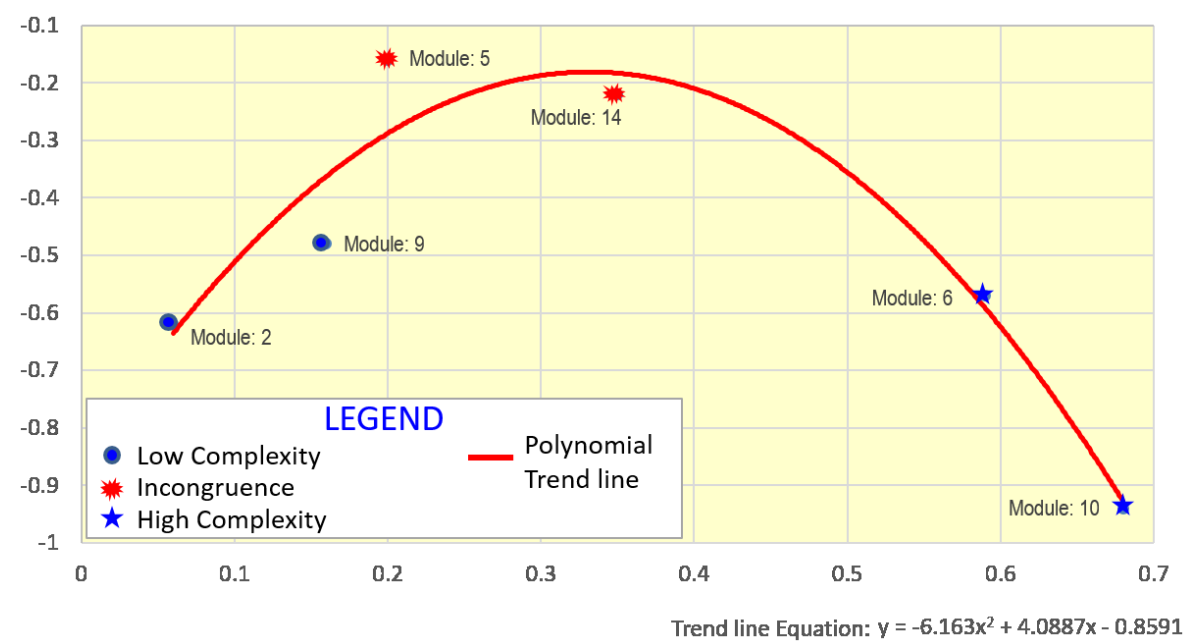

Figure 4: The Complexity experiment outcomes plotted

\section{References}

[1] Balfanz, R., Herzog, L., \& Mac Iver, D. (2007). Preventing student disengagement and keeping students on the graduation path in urban middle-grades schools: Early identification and effective interventions. Ecological Psychology, 42(4), 223-235.

[2] Bennett, K. B., Toms, M. L., \& Woods, D. D. (1993). Emergent reatures and graphical elements: Designing more effective configural displays. Human Factors: The Journal of the Human Factors and Ergonomics Society, 35(1), 71-97.

[3] Berlyne, D. E. (1963). Complexity and incongruity variables as determinants of exploratory choice and evaluative ratings. Canadian Journal of Psychology, 17(3), 274-290.

[4] Berlyne, D. E. (1970). Novelty, complexity and hedonic value. Perception and Psychophysics, 8(5A), 279-286.

[5] Brünken, R., Plass, J. L., \& Leutner, D. (2004). Assessment of cognitive load in multimedia learning with dual-task methodology: Auditory load and modality effects. Instructional Science, 32, 115-132.

[6] Butcher, K. R. (2003). Effects of diagram complexity on comprehension processes and learning outcomes. (3113068 Ph.D.), University of Colorado at Boulder, Colorado, USA. ProQuest Dissertations \& Theses Full Text database.

[7] Cohen, J. (1988). Statistical power analysis for the behavioral Sciences ( 2nd ed.). Hillsdale, New Jersey, USA: Erlbaum.

[8] Cummings, M. L., \& Tsonis, C. G. (2006). Partitioning complexity in air traffic management tasks. The International Journal of Aviation Psychology, 16(3), 277-295. doi:10.1207/s15327108ijap1603_3

[9] Day, H. (1967). Evaluations of subjective complexity, pleasingness and interestingness for a series of random polygons varying in complexity. Perception and Psychophysics, 2(7), 281-286.

[10] De Westelinck, K., Valcke, M., De Craene, B., \& Kirschner, P. (2005). Multimedia learning in social sciences: Limitations of external graphical representations. Computers in Human Behavior, 21(4), 555-573.

[11] Donderi, D. C. (2006). Visual complexity: A review. Psychological Bulletin, 132(1), 73-97. doi:10.1037/00332909.132.1.73

[12] Duarte, N. (2008). slide:ology. Sebastopol, California, USA: O'Reilly Media.

[13] Geissler, G. L., Zinkhan, G. M., \& Watson, R. T. (2006). The influence of home page complexity on consumer attention, attitudes and purchase intent. Journal of Advertising,
35(2), 69-80.

[14] Granger, B. P. (2012). Enhancing training outcomes in the context of e-Learning: The impact of objective learner control, training content complexity, cognitive load, learning goal orientation, and metacognitive strategies. (3545794 Ph.D.), University of South Florida, Florida, USA.

[15] Green, R. (1981). Remembering ideas from text: The effect of modality of presentation. British Journal of Educational Psychology, 51(1), 83-89. doi:10.1111/j.20448279.1981.tb02458.x

[16] Hilliard, B. A. (2016). Optimising viewer comprehension and shaping impressions and attention: through the formatting of content in tools like Microsoft PowerPoint. (PhD), Murdoch University, Perth, Western Australia.

[17] Hillyard, A. L. (1979). Stimulus complexity during original learning and generalization. (0353229 Ph.D.), University of Alberta (Canada), Alberta, Canada.

[18] Huff, M., \& Schwan, S. (2011). Integrating information from two pictorial animations: Complexity and cognitive prerequisites influence performance. Applied Cognitive Psychology, 25(6), 878-886. doi:10.1002/acp.1762

[19] Makaramanee, R. (1985). Pictorial stimulus complexity in texbooks (Design, Visual Aids, Grades 1-12 Analysis). (8528347 Ph.D.), Texas A\&M University, College Station, Texas, USA.

[20] Marks, H. M. (2000). Student engagement in instructional activity: Patterns in the elementary, middle and high school years. American Educational Research Journal, 37(1), 153184.

[21] McNamara, D. S., Kintsch, E., Songer, N. B., \& Kintsch, W. (1996). Are good texts always better? Interactions of text coherence, background knowledge, and levels of understanding in learning from text. Cognition and Instruction, 14(1), 1-43. doi:10.2307/3233687

[22] Mineo, B. A., Peischl, D., \& Pennington, C. (2008). Moving targets: The effect of animation on identification of action word representations. AAC: Augmentative $\& 3$ Alternative Communication, 24(2), 162-173.

[23] Moreno, R., \& Mayer, R. E. (1999). Cognitive principles of multimedia learning - The role of modality and contiguity. Journal of Educational Psychology, 91(2), 358-358.

[24] Paas, F., van Gog, T., \& Sweller, J. (2010). Cognitive Load Theory: New conceptualisations, specifications, and integrated research perspectives. Educational Psychology Review, 22, 115-121.

[25] Pathiavadi, C. S. (2009). Exploring efficient design ap- 
proaches for display of multidimensional data to facilitate interpretation of information. (3420611 Ph.D.), University of South Florida, Florida, USA.

[26] Rauterberg, M. (1994). About the relationship between incongruity, complexity and information: design implications for man-machine systems. In W. Rauch, F. Strohmeier, H. Hiller, \& C. Schlögl (Eds.), Mehrwert von Information - Professionalisierung der Informationsarbeit. Konstanz, Switzerland: Universitätsverlag.

[27] Rayner, K., Reichle, E. D., Stroud, M. J., Williams, C. C., \& Pollatsek, A. (2006). The effect of word frequency, word predictability, and font difficulty on the eye movements of young and older readers. Psychology and Aging, 21(3), 448448 .

[28] Roberts, M. N. (2007). Complexity and aesthetic preference for diverse visual stimuli. (Doctoral), Universitat de les Illes Balears, Palma, Spain.

[29] Rosenthal, J. A. (1996). Qualitative descriptors of strength of association and effect size. Journal of social service Research, 21(4), 37-59.

[30] Schnotz, W., \& Kurschner, C. (2007). A reconsideration of Cognitive Load Theory. Educational Psychology Review, 19, 469-508.

[31] Schnotz, W., \& Rasch, T. (2005). Enabling, facilitating, and inhibiting effects of animations in multimedia learning: Why reduction of cognitive load can have negative results on learning. Educational Technology, Research and Development, 53(3), 47-58.

[32] Surenda, N. S., Nikunj, D., \& Spears, N. (2005). Understanding web home page perception. European Journal of Information Systems (14), 288-302.

[33] Terwilliger, R. F. (1963). Pattern complexity and affective arousal. Perceptual and Motor Skills, 17(2), 387-395. doi:10.2466/pms.1963.17.2.387

[34] Thorson, E., Reeves, B., \& Schleuder, J. (1985). Message complexity and attention to television. Communication Research, 12(4), 427-454.

[35] Tuch, A. N., Bargas-Avila, J. A., Opwis, K., \& Wilhelm, F. H. (2009). Visual complexity of websites: Effects on users' experience, physiology, performance, and memory. International Journal of Human-Computer Studies, 67(9), 703-715.

[36] Tufte, E. R. (1990). Envisioning information. Cheshire, Connecticut, USA: Graphics Press.

[37] Tufte, E. R. (1997). Visual explanations: Images and quantities, evidence and narrative. Cheshire, Connecticut, USA: Graphic Press.

[38] Tufte, E. R. (2001). The visual display of quantitative information. Cheshire, Connecticut, USA: Graphic Press.

[39] Vitz, P. C. (1966). Preference for different amounts of visual complexity. Psychology / Social Sciences (General), 11(2), 105-114.

[40] Wang, Q., Yang, S., Liu, M., Cao, Z., \& Ma, Q. (2014). An eye-tracking study of website complexity from cognitive load perspective. Decision Support Systems, 62, 1-10.

[41] Wu, O., Hu, W., \& Shi, L. (2013). Measuring the visual complexities of web pages. ACM Trans. Web, 7(1), 1-34.doi:10.1145/2435215.2435216 